\title{
First results on a process-oriented rain area classification technique using Meteosat Second Generation SEVIRI nighttime data
}

\author{
B. Thies, T. Nauss, and J. Bendix \\ Laboratory for Climatology and Remote Sensing, Philipps-University Marburg, Germany \\ Received: 31 August 2007 - Revised: 1 September 2007 - Accepted: 29 January 2008 - Published: 9 April 2008
}

\begin{abstract}
A new technique for process-oriented rain area classification using Meteosat Second Generation SEVIRI nighttime data is introduced. It is based on a combination of the Advective Convective Technique (ACT) which focuses on precipitation areas connected to convective processes and the Rain Area Delineation Scheme during Nighttime (RADS-N) a new technique for the improved detection of stratiform precipitation areas (e.g. in connection with mid-latitude frontal systems). The ACT which uses positive brightness temperature differences between the water vapour (WV) and the infrared (IR) channels $\left(\Delta T_{\mathrm{WV}-\mathrm{IR}}\right)$ for the detection of convective clouds and connected precipitating clouds has been transferred from Meteosat First Generation (MFG) Metesoat Visible and Infra-Red Imager radiometer (MVIRI) to Meteosat Second Generation (MSG) Spinning Enhanced Visible and InfraRed Imager (SEVIRI). RADS-N is based on the new conceptual model that precipitating cloud areas are characterised by a large cloud water path (cwp) and the presence of ice particles in the upper part of the cloud. The technique considers information about both parameters inherent in the channel differences $\Delta T_{3.9-10.8}, \Delta T_{3.9-7.3}, \Delta T_{8.7-10.8}$, and $\Delta T_{10.8-12.1}$, to detect potentially precipitating cloud areas. All four channel differences are used to gain implicit knowledge about the $c w p . \Delta T_{8.7-10.8}$ and $\Delta T_{10.8-12.1}$ are additionally considered to gain information about the cloud phase. First results of a comparison study between the classified rain areas and corresponding ground based radar data for precipitation events in connection with a cold front occlusion show encouraging performance of the new proposed process-oriented rain area classification scheme.
\end{abstract}

Correspondence to: $\mathrm{B}$. Thies

(thies@1crs.de)

\section{Introduction}

The estimation of precipitation by means of geostationary weather satellites has a long tradition as they provide areawide information about the distribution of this major factor of the global water cycle in a spatially and temporally high resolution.

Most of the retrieval techniques developed so far rely on the relationship between cloud top temperature in the infrared channel and the rainfall probability and rate (e.g. Adler and Negri, 1988). Such IR retrievals are appropriate for deep convective clouds that can be easily identified in the infrared and/or water vapour channels (e.g. Levizzani et al., 2001; Levizzani, 2003) but show considerable drawbacks in the mid-latitudes (e.g. Ebert et al., 2007; Früh et al., 2007), where great parts of the precipitation originates from clouds formed by widespread frontal lifting processes in connection with extra-tropical cyclones (hereafter denoted as advectivestratiform precipitation).

These clouds are characterized by relatively warm top temperatures and a more homogeneous spatial distribution of cloud top temperature that differ not significantly between raining and non-raining regions. Therefore, a threshold value for cloud top temperature in the IR channel as used for deep convective clouds seems to be improper for a reliable rain area delineation and leads to an underestimation of the detected precipitation area in such cases.

Recently, an improved technique for the detection of enhanced advective-stratiform precipitating cloud areas associated to convective precipitation processes in the upper parts of the cloud (i.e. enhancement by generating cells in connection with embedded convection; refer to Houze, 1993) has been proposed for MFG MVIRI (Reudenbach et al., 2007). The so-called ACT is based on the Enhanced Convective Stratiform Technique (ECST; Reudenbach, 2003; Reudenbach et al., 2001), an improved version of the ConvectiveStratiform Technique (CST; Adler and Negri, 1988; Bendix,

Published by Copernicus Publications on behalf of the European Geosciences Union. 
1997) which additionally uses the positive brightness temperature difference between the water vapour (WV) and the infrared (IR) channels $\left(\Delta T_{\mathrm{WV}-\mathrm{IR}}\right)$ of MVIRI (see Schmetz et al., 1997; Tjemkes et al., 1997) for a more reliable detection of deep convective clouds (Kurino, 1997).

The phenomenon of positive $\Delta T_{\mathrm{WV}-\mathrm{IR}}$ is caused by the presence of water vapour in the lower stratosphere above the cloud (Fritz and Laszlo, 1993) which is transported there by deep convection with overshooting tops (e.g. Page, 1982; Kley et al., 1982). When the cloud top approaches the tropopause, it blocks lower tropospheric radiation from escaping into space and hence, the received signal at the satellite level originates from the cloud top and the atmosphere aloft. As the temperature in the stratosphere increases with height, the water vapour above the cloud absorbs outgoing radiation from the high cloud top and emits radiation at higher temperatures. Because of the stronger water vapour absorption lines in the WV channel compared to the IR channel of MVIRI this results in higher brightness temperatures in the WV channel. As a result, the actual brightness temperature difference depends on the amount of stratospheric water vapour and the location of the cloud top with respect to the tropopause. Largest values for $\Delta T_{\mathrm{WV}-\mathrm{IR}}$ are calculated when the cloud top reaches the tropopause inversion, where the brightness temperature in the IR channel is at a minimum (Schmetz et al., 1997; Tjemkes et al., 1997).

However, the ACT focuses only on precipitation areas connected to convective precipitation processes. This still leads to an underestimation of the detected rain area, because precipitation fields formed by widespread uplifting processes in connection with extratropical cyclones which are not connected with convective processes (hereafter referred to as advective-stratiform background precipitation; refer to Houze, 1993) are omitted.

In this context Thies et al. (2008) introduced a new rain area delineation scheme during nighttime for MSG SEVIRI which is based on the new conceptual model that precipitating cloud areas are characterised by a sufficiently large cloud water path ( $c w p)$ and the existence of ice particles in the upper cloud parts. It shows a significant improvement compared to existing retrieval techniques using only a IR threshold for cloud top temperature. This holds especially true for the above mentioned areas of advective-stratiform background precipitation.

A combination of ACT and RADS-N using MSG SEVIRI would enable an extended process-oriented classification of the detected rain area. Such a classification can form the basis for an improved rainfall rate assignment. This paper presents a first investigation of the potential regarding a process classification by merging both retrieval techniques.

As mentioned above, positive $\Delta T_{\mathrm{WV}-\mathrm{IR}}$ form the basis for the detection of convective clouds within the ACT. Of special interest in this context are the two water vapour $\left(W V_{6.2}\right.$ : 5.35-7.15 $\left.\mu \mathrm{m} ; W V_{7.3}: 6.85-7.85 \mu \mathrm{m}\right)$ and the two infrared channels ( $\left.I R_{10.8}: 9.8-11.8 \mu \mathrm{m} ; I R_{12.1}: 11.0-13.0 \mu \mathrm{m}\right)$ of
SEVIRI. Because of its differing spectral resolution with regard to MVIRI (WV: 5.7-7.1 $\mu \mathrm{m}$; IR: 10.5-12.5 $\mu \mathrm{m}$ ), it has to be examined if and how the brightness temperature difference between the WV and the IR channels of SEVIRI can be used to delineate high rain clouds equal to MVIRI. A successful adaptation of this technique is the precondition for a proper transfer of the ACT to MSG SEVIRI and a combination with RADS-N. The effectual transfer of the ACT to MSG SEVIRI and its combination with RADS-N enable the process-oriented classification of the identified rainfall area.

\section{Introduction of the retrieval techniques}

\subsection{ACT}

The ACT represents an extension of the ECST originally developed for Meteosat MVIRI. The use of the WV-IRbrightness temperature differences in the ECST for the delineation of high rain clouds is described in detail by Reudenbach et al. (2001) and Reudenbach (2003). Generally, positive brightness temperature differences between the MVIRI $\mathrm{WV}$ and the IR channel indicate high rain clouds. In the ECST, positive $\Delta T_{\mathrm{WV}-\mathrm{IR}}$ thresholds are statistically subdivided to distinguish between three classes of raining cloud areas: (1) active convective areas with high precipitation intensities, (2) decaying convective areas within Nimbostratus clouds of enhanced stratiform precipitation intensities and (3) clouds with convective-stratiform precipitation intensities in the adjacent environment of active convective areas.

The module for the detection of enhanced advectivestratiform precipitating cloud areas (4) associated to convective precipitation processes in the upper parts of the cloud is based on an iterative k-means clustering algorithm (Bradley and Fayyad, 1998) that is applied to $T_{\mathrm{IR}}, T_{\mathrm{WV}}$ and a synthetic channel representing the standard deviation of 3 by 3 pixels in the IR channel $\left(S t d v_{\text {IR }}\right)$. It integrates the classified cloud patterns from the ECST as core raining areas. Each cluster is reallocated into single cloud entities for which the compactness is calculated. A cluster is classified as raining by means of a discriminant function based on the cluster centroid temperature, the compactness of the cloud entity, and the number of embedded, isolated convective cores (refer to Reudenbach et al., 2007).

\subsection{RADS-N}

The RADS-N is based on the new conceptual model that precipitation is favoured by a large cloud liquid or ice water path $(c w p)$ and the presence of ice particles in the upper part of the cloud. The technique considers information about both parameters inherent in the channel differences $\Delta T_{3.9-10.8}$, $\Delta T_{3.9-7.3}, \Delta T_{8.7-10.8}$, and $\Delta T_{10.8-12.1}$, to detect potentially precipitating cloud areas. All four channel differences are used to gain implicit knowledge about the $c w p . \Delta T_{8.7-10.8}$ 
and $\Delta T_{10.8-12.1}$ are additionally considered to gain information about the cloud phase. The information inherent in all four channel differences is merged and incorporated into the rain delineation algorithm (refer to Thies et al., 2008).

Based on the findings of several case studies, Thies et al. (2008) used radiative transfer calculations to demonstrate that implicit information about the cloud water path as well as about the cloud phase is available from the above mentioned four channel differences. To make use of this implicit information content they calculated rainfall confidences for the combination of the four temperature differences and showed that intervals of the channel differences representative of high rainfall confidences correspond with the intervals indicative for large $c w p$ and ice clouds (i.e. potentially precipitating cloud areas). Based on these results, rain area delineation is realized by a minimum threshold for the calculated rainfall confidences for the four temperature differences.

The retrieval shows an encouraging performance as well as clear improvements compared to existing optical retrieval techniques using only IR thresholds for cloud top temperature. It allows not only a proper detection of mainly convective precipitation by means of the commonly used connection between infrared cloud top temperature and rainfall probability, but also enables the detection of stratiform precipitation (e.g., in connection with mid-latitude frontal systems).

\section{Transfer of the ACT to MSG SEVIRI}

The phenomenon of positive brightness temperature differences between the WV and IR channels $\left(\Delta T_{\mathrm{WV}-\mathrm{IR}}\right)$, which enables the detection of high rain clouds and forms the basis for the ACT rainfall retrieval, has been investigated for the WV-IR channel combinations of SEVIRI.

3.1 Positive $\Delta T_{\mathrm{WV}-\mathrm{IR}}$ for the detection of convective clouds

The availability of positive $\Delta T_{\mathrm{WV}-\mathrm{IR}}$ for the different SEVIRI WV-IR combinations was tested using the radiative transfer model Streamer (Key, 2001; Key and Schweiger, 1998). To check if positive $\Delta T_{\mathrm{WV}-\mathrm{IR}}$ for the four SEVIRI WV-IR combinations enable an appropriate detection of high-level rain clouds, the 12:00 LT radiosonde profile from Essen, Germany, for the highly convective Colognehail storm on 4 July 1994 was utilized for the radiative transfer calculations (refer to Reudenbach, 2003). An optically thick cloud with a base height of $2 \mathrm{~km}$ and parameterised optical and microphysical cloud properties typical for deep convective Cumulonimbus clouds (Zhang and Hongbin, 2006; Schemenauer and Isaac, 1984) was used. Table 1 summarizes the relevant input parameters used in the calculations. The settings are applied to simulate the resulting cloud top temperatures in each SEVIRI WV and IR channel.

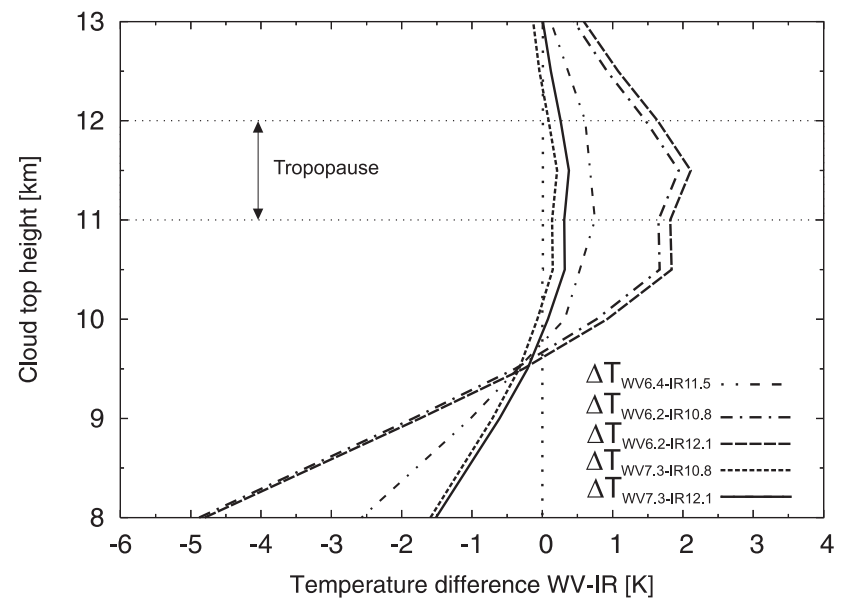

Fig. 1. Simulated $\Delta T_{\mathrm{WV}-\mathrm{IR}}$ for each WV-IR channel combination of SEVIRI and MVIRI ( $\left.\Delta T_{\mathrm{WV} 6.4-\mathrm{IR} 11.5}\right)$ as a function of cloud top height.

To get an idea of the development of $\Delta T_{\mathrm{WV}-\mathrm{IR}}$ for a rising cumulus the vertical extension of the cloud was varied between 6 and $11 \mathrm{~km}$. The calculated $\Delta T_{\mathrm{WV}-\mathrm{IR}}$ for different cloud top heights for each WV-IR combination of SEVIRI as well as of MVIRI is depicted in Fig. 1. As the cloud top rises, $\Delta T_{\mathrm{WV}-\mathrm{IR}}$ increases and the maximum temperature difference is observed when the cloud reaches the tropopause at about $11.5 \mathrm{~km}$ which is indicated in the radiosonde profile by an isothermal layer between 11 and $12 \mathrm{~km}$. Then $\Delta T_{\mathrm{WV}-\mathrm{IR}}$ decreases again because the water vapour amount above the cloud top decreases with further cloud top rising. The results of the radiative transfer calculations for SEVIRI and MVIRI resemble each other and agree quite well with the findings of Schmetz et al. (1997) and Tjemkes et al. (1997) for MVIRI. Therefore, it is concluded that the approach to detect convective cores by means of positive temperature differences between the WV and the IR channel can be transferred to SEVIRI which also implies the option to transfer the ACT to SEVIRI.

The varying amount of the calculated $\Delta T_{\mathrm{WV}-\mathrm{IR}}$ for each WV-IR combination can be explained by the channels spectral range and spectral response function (SRF). For a more detailed investigation of this phenomenon, radiative transfer calculations were performed for each channel for both a cloud free atmosphere and a cloud reaching the tropopause with a top height at $12 \mathrm{~km}$ channel. The results are displayed in Fig. 2. Note that the calculated temperatures in Fig. 2 are not weighted by the SRF of the respective channel. This was done to allow a detailed analysis of the calculated temperatures over the complete spectral range of each channel.

In a cloud free atmosphere (Fig. 2 upper panel) the radiation in the infrared channels originates from the surface and the lower troposphere. Generally, the signal in the 11.0 $13.0 \mu \mathrm{m}$ interval $\left(I R_{12.1} ;\right.$ Fig. 2 a comes from slightly higher 
Table 1. Input parameters for the radiative transfer calculations; $R_{\mathrm{e}}$ (effective droplet radius), $D_{\mathrm{e}}$ (effective particle radius), LWC (liquid water content), IWC (ice water content).

\begin{tabular}{ccccccc}
\hline Solar zenith angle & Satellite zenith angle & Relative azimuth angle & $R_{\mathrm{e}}$ & $\mathrm{LWC}$ & $D_{\mathrm{e}}$ & IWC \\
& & & {$[\mu \mathrm{m}]$} & {$\left[\mathrm{g} / \mathrm{m}^{3}\right]$} & {$[\mu \mathrm{m}]$} & {$\left[\mathrm{g} / \mathrm{m}^{3}\right]$} \\
$45^{\circ}$ & $55^{\circ}$ & $130^{\circ}$ & 30 & 0.5 & 60 & 0.07 \\
\hline
\end{tabular}
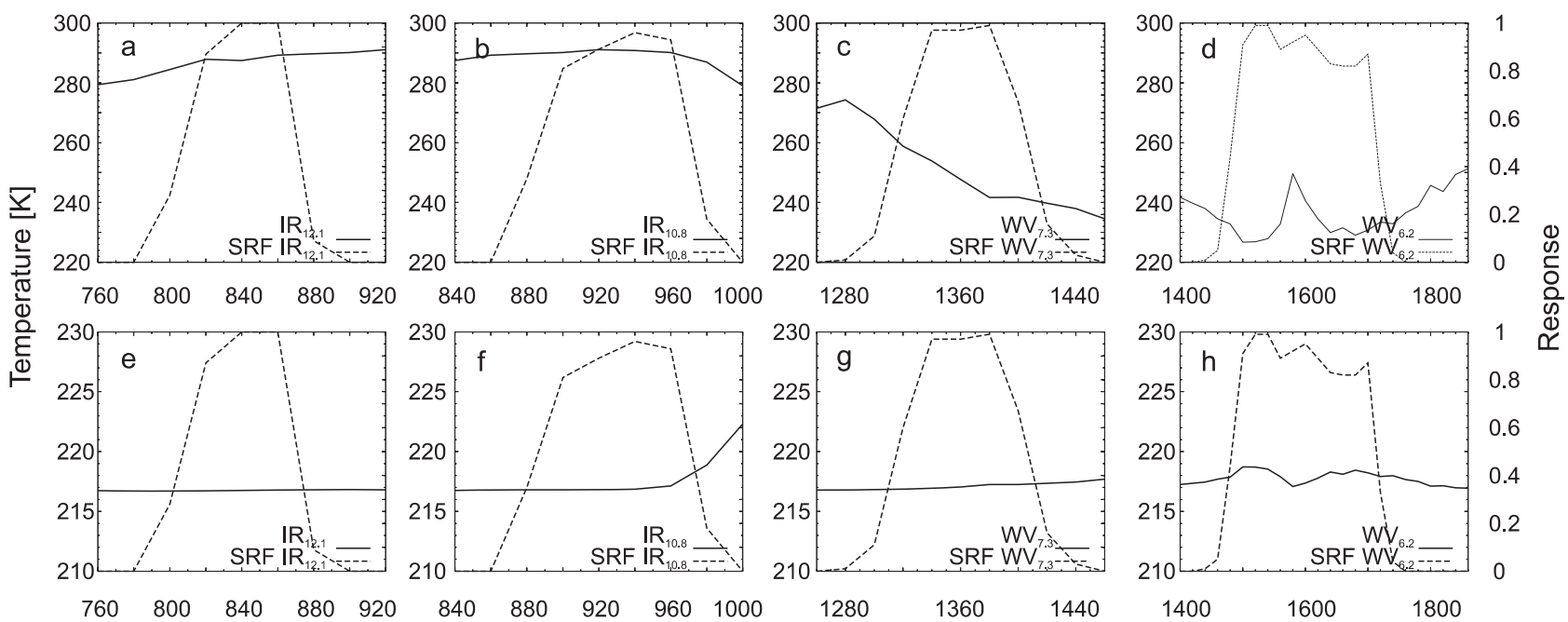

Wavenumber $\left[\mathrm{cm}^{-1}\right]$

Fig. 2. Results of the radiative transfer calculations for the spectral ranges of the SEVIRI WV-IR channel combinations (solid line) together with the SRF for each channel (dotted line). (a) to (d) results for cloud free atmosphere: (a) IR 11.0-13.0 $\mu \mathrm{m}$ (I $\left.R_{12.1}\right)$; (b) IR 9.8-11.8 $\mu \mathrm{m}$ $\left(I R_{10.8}\right)$; (c) WV 6.85-7.85 $\mu \mathrm{m}\left(W V_{7.3}\right)$; (d) WV 5.35-7.15 $\mu \mathrm{m}\left(W V_{6.2}\right)$. (e) to (h) results for a cloud top at 12 km: (e) IR 11.0-13.0 $\mu \mathrm{m}$ $\left(I R_{12.1}\right)$; (f) IR 9.8-11.8 $\mu \mathrm{m}\left(I R_{10.8}\right)$; (g) WV 6.85-7.85 $\mu \mathrm{m}\left(W V_{7.3}\right)$; (h) WV 5.35-7.15 $\mu \mathrm{m}\left(W V_{6.2}\right)$.

parts in the troposphere compared to the 9.8-11.8 $\mu \mathrm{m}$ interval ( $I R_{10.8}$; Fig. $2 \mathrm{~b}$, see also Schmetz et al., 2002). This is due to its higher sensitivity to water vapour absorption (Kleespies and McMillin, 1990) resulting in an emission spectrum at higher altitudes and lower temperatures. Integrated and weighted with the exact SRF, the brightness temperature in the $I R_{12.1}$ channel is colder than in the $I R_{10.8}$ channel.

The 5.35-7.15 $\mu \mathrm{m}$ interval ( $W V_{6.2}$; Fig. 2(d) covers the centre of the water vapour absorption band, whereas the 6.85-7.85 $\mu \mathrm{m}$ interval $\left(W V_{7.3}\right.$; Fig. 2(c) is positioned closer to its edge. Consequently, the main part of the radiation in the $W V_{6.2}$ channel originates from higher parts of the troposphere $(\approx 300 \mathrm{hPa}$ level; see Schmetz et al., 2002) compared to the $W V_{7.3}$ channel where the radiation originates also from lower layers $(\approx 500 \mathrm{hPa}$ level; see Schmetz et al., 2002). Integrated over the spectral interval and taking into account the exact SRF, the brightness temperature in the $W V_{6.2}$ channel is colder than in the $W V_{7.3}$ channel.

When an opaque cloud is inserted in the profile at the level of the tropopause (Fig. 2 lower panel), radiation from the troposphere is blocked from escaping into space and the re- ceived radiation originates from cloud top and stratospheric emissions. As the temperature in the stratosphere increases with height, the emission in the $I R_{10.8}$ channel results in higher temperatures than in the $I R_{12.1}$ channel since the absorption at the edge of the $I R_{10.8}$ channel increases slightly (Fig. 2f). Integrated over the spectral region and considering the SRF of the infrared channels, this leads to higher temperatures in the $I R_{10.8}$ as compared to the $I R_{12.1}$ channel. The absorption lines in the $W V_{6.2}$ channel (Fig. 2h) are stronger throughout the entire spectral region compared to the $W V_{7.3}$ channel (Fig. $2 \mathrm{~g}$ ) resulting in higher temperatures in the $W V_{6.2}$ channel for the cloudy case.

In the light of the results depicted in Fig. 2 the differences concerning the calculated $\Delta T_{\mathrm{WV}-\mathrm{IR}}$ for each SEVIRI WV-IR combination (see Fig. 1) can be explained as follows. For cloud tops below the tropopause the temperature in the $W V_{6.2}$ channel is lower than in the $W V_{7.3}$ channel and the temperature in the $I R_{10.8}$ channel is higher than in the $I R_{12.1}$ channel. Thus, the minimum and maximum temperature differences are obtained by the $W V_{6.2}-I R_{10.8}$ and $W V_{7.3}-I R_{12.1}$ combinations respectively (see Fig. 1). When the cloud top reaches the tropopause and tropospheric radi- 
Table 2. Calculated validation scores for 80 spatially and temporally corresponding MVIRI and SEVIRI based ACT results between July and August 2004.

\begin{tabular}{lcccccccc}
\hline & $\begin{array}{c}\text { Rain Area } \\
\text { SEVIRI [\%] }\end{array}$ & $\begin{array}{c}\text { Rain Area } \\
\text { MVIRI [\%] }\end{array}$ & Bias & POD & FAR & CSI & ETS & HSS \\
\hline Whole area ACT & & & & & & & \\
\hline$\Delta T_{\text {WV6.2-IR10.8 }}$ & 3.22 & 6.91 & 0.47 & 0.38 & 0.22 & 0.34 & 0.32 & 0.48 \\
$\Delta T_{\text {WV6.2-IR12.1 }}$ & 3.53 & 6.91 & 0.51 & 0.41 & 0.22 & 0.36 & 0.34 & 0.51 \\
$\Delta T_{\text {WV7.3-IR10.8 }}$ & 5.43 & 6.91 & 0.79 & 0.57 & 0.28 & 0.47 & 0.44 & 0.61 \\
$\Delta T_{\text {WV7.3-IR12.1 }}$ & 6.24 & 6.91 & 0.90 & 0.62 & 0.31 & 0.48 & 0.46 & 0.62 \\
\hline Advective-stratiform & & & & & & & & \\
\hline$\Delta T_{\text {WV6.2-IR10.8 }}$ & 2.14 & 3.15 & 0.68 & 0.19 & 0.73 & 0.12 & 0.11 & 0.20 \\
$\Delta T_{\text {WV6.2-IR12.1 }}$ & 2.17 & 3.15 & 0.69 & 0.20 & 0.71 & 0.13 & 0.12 & 0.21 \\
$\Delta T_{\text {WV7.3-IR10.8 }}$ & 2.75 & 3.15 & 0.87 & 0.27 & 0.68 & 0.16 & 0.15 & 0.26 \\
$\Delta T_{\text {WV7.3-IR12.1 }}$ & 2.93 & 3.15 & 0.93 & 0.29 & 0.68 & 0.17 & 0.16 & 0.27 \\
\hline Convective-stratiform & & & & & & & & \\
\hline$\Delta T_{\text {WV6.2-IR10.8 }}$ & 0.82 & 2.87 & 0.28 & 0.17 & 0.40 & 0.15 & 0.16 & 0.26 \\
$\Delta T_{\text {WV6.2-IR12.1 }}$ & 1.07 & 2.87 & 0.37 & 0.23 & 0.39 & 0.20 & 0.19 & 0.31 \\
$\Delta T_{\text {WV7.3-IR10.8 }}$ & 2.06 & 2.87 & 0.72 & 0.41 & 0.43 & 0.31 & 0.30 & 0.45 \\
$\Delta T_{\text {WV7.3-IR12.1 }}$ & 2.93 & 2.87 & 1.02 & 0.55 & 0.46 & 0.38 & 0.35 & 0.52 \\
\hline Active convective cores & & & & & & & & \\
\hline$\Delta T_{\text {WV6.2-IR10.8 }}$ & 0.14 & 0.70 & 0.19 & 0.05 & 0.74 & 0.04 & 0.04 & 0.08 \\
$\Delta T_{\text {WV6.2-IR12.1 }}$ & 0.17 & 0.70 & 0.24 & 0.06 & 0.74 & 0.05 & 0.05 & 0.09 \\
$\Delta T_{\text {WV7.3-IR10.8 }}$ & 0.35 & 0.70 & 0.49 & 0.11 & 0.78 & 0.08 & 0.07 & 0.13 \\
$\Delta T_{\text {WV7.3-IR12.1 }}$ & 0.47 & 0.70 & 0.66 & 0.14 & 0.79 & 0.09 & 0.08 & 0.15 \\
\hline Decaying convective cores & & & & & & & \\
\hline$\Delta T_{\text {WV6.2-IR10.8 }}$ & 0.02 & 0.13 & 0.16 & 0.00 & 0.98 & 0.00 & 0.00 & 0.00 \\
$\Delta T_{\text {WV6.2-IR12.1 }}$ & 0.02 & 0.13 & 0.18 & 0.00 & 0.98 & 0.00 & 0.00 & 0.00 \\
$\Delta T_{\text {WV7.3-IR10.8 }}$ & 0.08 & 0.13 & 0.62 & 0.01 & 0.99 & 0.01 & 0.00 & 0.01 \\
$\Delta T_{\text {WV7.3-IR12.1 }}$ & 0.09 & 0.13 & 0.68 & 0.01 & 0.99 & 0.01 & 0.00 & 0.01 \\
& & & & & & & &
\end{tabular}

ation is blocked, the temperature in the $W V_{6.2}$ channel becomes higher than in the $W V_{7.3}$ channel, whereas the temperature in the $I R_{10.8}$ channel remains slightly higher than in the $I R_{12.1}$ channel. Therefore, minimum and maximum temperature differences are calculated for the $W V_{7.3}-I R_{10.8}$ and the $W V_{6.2}-I R_{12.1}$ combination respectively (see Fig. 1).

3.2 Statistical comparison of the ACT results based on MVIRI and on SEVIRI

For a successful transfer of the ACT algorithm to SEVIRI, it has to be analysed which of the four possible WV-IR SEVIRI combinations yield the best results in reproducing the MVIRI retrieval. Therefore, the retrieved rain area by the ACT based on MVIRI data are compared to SEVIRI based ACT results. Temporally and spatially corresponding data from MVIRI and SEVIRI required for this study are available between 2004 and 2006. The current study is conducted for Central Europe and is based on 80 simultaneous MVIRI/SEVIRI scenes of July and August 2004 with sufficient precipitation intensities.

The ACT has been adapted to SEVIRI using the four possible WV-IR combinations. For a proper comparison of the ACT results, MVIRI based maps were projected to the SE-
VIRI viewing geometry. The indirect validation of the different SEVIRI WV-IR combinations with the corresponding MVIRI retrieval is conducted by applying standard validation scores for dichotomous datasets: (i) bias, (ii) probability of detection (POD), (iii) false alarm ratio (FAR), (iv) critical success index (CSI), (v) equitable threat score (ETS), and (vi) heidke skill score (HSS). For a detailed discussion of the verification scores see Stanski et al. (1989) or the web site of the WWRP/WGNE (2007). The statistics were calculated separately for each rainfall class (active convective cores, decaying convective cores, convective-stratiform, enhanced advective-stratiform) and for the entire rain area.

The calculated validation scores used for this analysis are summarized in Table 2 . In general, the $\Delta T_{\mathrm{WV} 7.3-\mathrm{IR} 12.1}$ combination reveals the highest accordance with the MVIRI based results regardless if the entire rainfall area or one of the four individual classes is considered. The calculated validation scores indicate good agreement between the two sensors with the highest quality for the entire rain area identified by the ACT, for the classified area with enhanced advectivestratiform precipitation, and for the classified convectivestratiform precipitation area. On the other hand, the scores reflect a lower level of agreement for the detected active convective areas and decaying convective cores. This is caused 

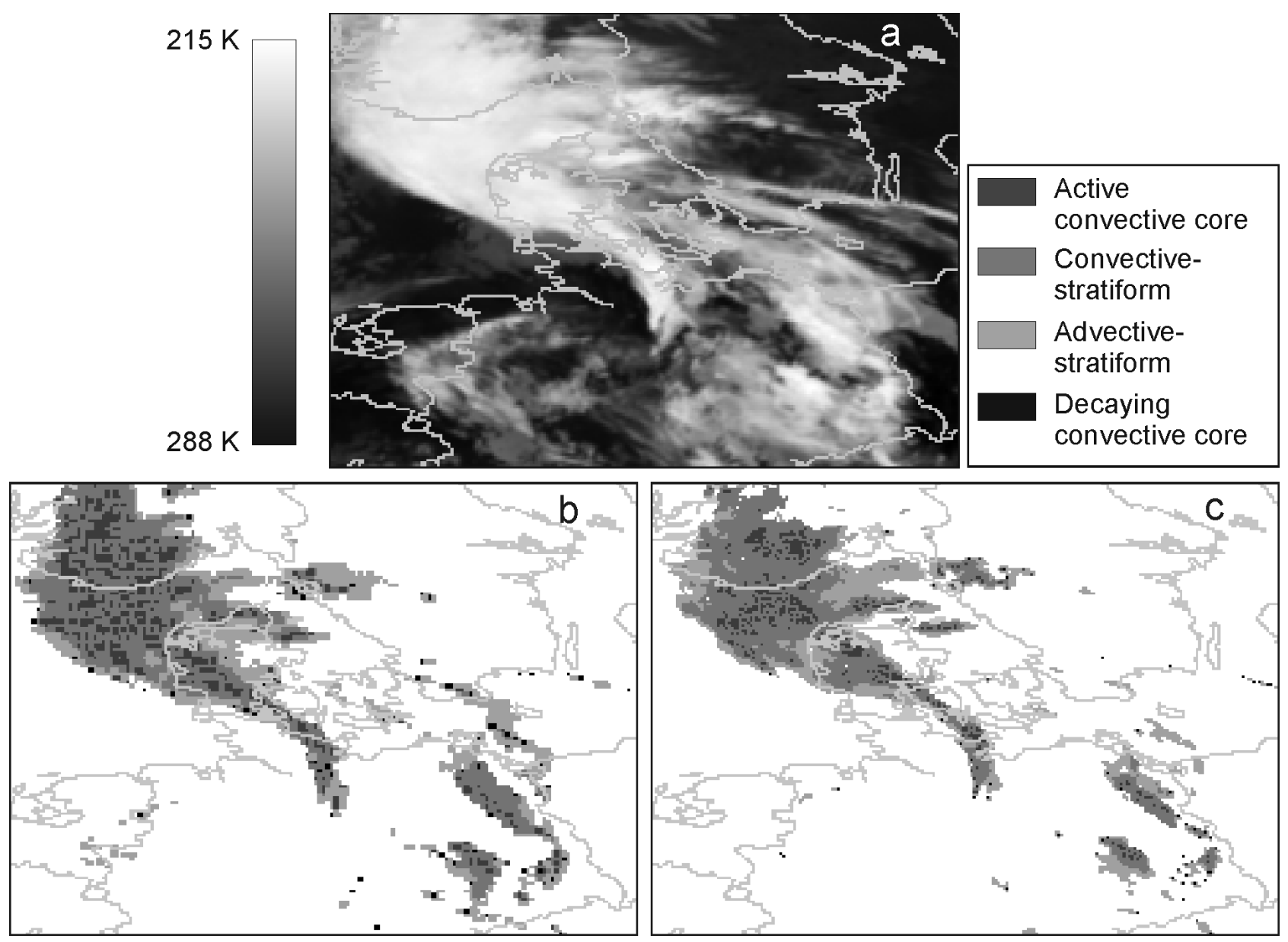

Fig. 3. Brightness temperature $[\mathrm{K}]$ in the $I R_{10.8}$ channel (a), MVIRI-based ACT results (b), ACT results based on the SEVIRI $W V_{7.3-}$ $I R_{12.1}$ combination (c) for the 18 July 2004 1:00 UTC.

by the higher spatial resolution of the SEVIRI data (3 by $3 \mathrm{~km}$ at nadir) leading to smaller and more fractional areas of the detected pixels of active convection and decaying convection. Along with the projection of the MVIRI based ACT results ( 5 by $5 \mathrm{~km}$ at nadir) to the SEVIRI viewing geometry this cause spatial misalignments between both data sets regarding the classified pixels. Such a projection is necessary because of the differing viewing geometries between both systems. The projection which is realized by a backward resampling with next neighbour can lead to slight spatial misalignments which are potentially reinforced by the lower spatial resolution of MVIRI compared to SEVIRI. Because of the lower fraction of the classified rain area (see percentage rain area in Table 2) these spatial misalignments have a strong influence on the quality of the calculated verification scores for the active convective and the decaying convective core areas. This interpretation is supported by the fact that despite the low quality of the validation results indicated by the POD, FAR, CSI, ETS, and HSS scores, the Bias and the fraction of the classified rain area are in good accordance between the MVIRI and the SEVIRI based results for the active convective and the decaying convective core areas.

Based on the results of the comparison study, the SEVIRI $\Delta T_{\mathrm{WV} 7.3-\mathrm{IR} 12.1}$ combination is identified as the appropriate channel combination to reproduce the results of the MVIRI based ACT. As a consequence, the ACT can be transferred from MVIRI to SEVIRI.

A visual inspection of the ACT results in Fig. $3 b$ and $c$ reveals that the spatial patterns of the identified precipitation areas correspond quite well between both data sets. Because of the higher spatial resolution of SEVIRI, the ECST result based on the $W V_{7.3}-I R_{12.1}$ combination is characterized by a more differentiated image especially concerning the detected active convective cores. Those form smaller and less contiguous areas compared to the MVIRI results. This can be an explanation for the underestimation regarding the active convective cores indicated by the bias in Table 2 . 
Table 3. Overview of the classified subareas (ID) within the detected rain area by the new process-oriented classification scheme (ACT plus RADS-N) and by the radar network together with corresponding radar reflectivity and the rainfall rate.

\begin{tabular}{|c|c|c|c|c|}
\hline ID & ACT plus RADS-N & Radar & $\begin{array}{c}\text { Radar reflectivity } \\
{[\mathrm{dBZ}]}\end{array}$ & $\begin{array}{c}\text { Rainfall rate } \\
{[\mathrm{mm} / \mathrm{h}]}\end{array}$ \\
\hline 1 & $\begin{array}{l}\text { precipitation from active } \\
\text { convective cores and } \\
\text { from decaying cores }\end{array}$ & $\begin{array}{l}\text { very high rainfall } \\
\text { intensities with } \\
\text { thunderstorms }\end{array}$ & 7.0 to 27.9 & 0.06 to 1.8 \\
\hline 2 & $\begin{array}{l}\text { convective stratiform } \\
\text { precipitation }\end{array}$ & $\begin{array}{l}\text { moderate to high rainfall } \\
\text { intensities possibly with } \\
\text { thunderstorms }\end{array}$ & 28.0 to 36.9 & 1.9 to 8.0 \\
\hline 3 & $\begin{array}{l}\text { enhanced advective- } \\
\text { stratiform precipitation }\end{array}$ & $\begin{array}{l}\text { moderate rainfall } \\
\text { intensities }\end{array}$ & 37.0 to 45.9 & 8.1 to 34.9 \\
\hline 4 & $\begin{array}{l}\text { advective-stratiform } \\
\text { background precipitation }\end{array}$ & $\begin{array}{l}\text { light to moderate } \\
\text { rainfall intensities }\end{array}$ & $\geq 46.0$ & $\geq 35.0$ \\
\hline
\end{tabular}

\section{Process-oriented rain area classification}

Following the successful transfer of the ACT to MSG SEVIRI, the next step, a classification of the rainfall processes within the detected rain area, can be addressed.

The ACT enables a classification into (1) active convective areas with high precipitation intensities, (2) decaying convective areas within Nimbostratus clouds of enhanced stratiform precipitation intensities, (3) clouds with convectivestratiform precipitation intensities in the adjacent environment of active convective areas, and (4) cloud areas of enhanced advective-stratiform precipitation intensities associated to convective processes in the upper parts of the cloud. RADS-N shows significant improvements concerning the detection of (5) advective-stratiform background precipitation areas (refer to Houze (1993) for a detailed discussion of the respective precipitation areas with differing rainfall intensities).

Therefore, a combination of the ACT and RADS-N permits an extended process-oriented classification of the detected rain area into the following five classes characterised by different rainfall intensities:

1. precipitation from active convective cores

2. precipitation from decaying convective cores within Nimbostratus clouds

3. convective-stratiform precipitation

4. enhanced advective-stratiform precipitation

5. advective-stratiform background precipitation

Within the detected rain area by RADS-N the ACT is applied to classify the above mentioned subareas of differing precipitation processes and rainfall intensities.

\section{Evaluation and case study}

To gain a first impression of the performance of the new proposed process-oriented classification scheme the classified subareas detected by the new technique are compared to ground based radar data by applying standard verification scores for dichotomous data. The dataset consists of 46 scenes between 30 and 31 May. During this time a cold front occlusion producing moderate to high rainfall intensities together with some isolated thunderstorms passed Germany from the southwest to the northeast. The statistics were calculated separately for each identified area (refer to Table 3). The radar data have an original spatial resolution of 4 by $4 \mathrm{~km}^{2}$ and were projected to the viewing geometry of SEVIRI with spatial resolution of 3 by $3 \mathrm{~km}^{2}$ for the calculation of the statistical indices. As the radar data is concerned as the reference dataset in this comparison study it has to be mentioned that precipitation estimation with radar is also connected with problems. The ground clutter problem, super refraction of the radar beam due to temperature inversions in the atmosphere and attenuation of the radar beam by precipitation particles pose the greatest problems in this context (e.g. Lang, 1997; Seltmann, 1997). The calculated indices are summarized in Table 4.

The subareas with different rainfall intensities detected by the new classification scheme (ACT plus RADS-N) and the radar network are in good accordance to each other. The bias for ID 2, ID 3 and ID 4 indicates a good agreement with the areas detected by the radar network. The bias for ID 1 points to a relatively high overestimation for this subarea by the new classification technique compared to the radar dataset. Regarding the absolute pixel amount for ID1 this high overestimation is relativized somewhat.

The spatial misalignments between both techniques might be the result of the differing viewing geometry between the satellite scanning the cloud top and the ground based radar network scanning the cloud bottom and detecting the rainfall 
Table 4. Calculated verification scores for the classified subareas (ID) by the new process-oriented classification scheme (ACT plus RADS$\mathrm{N}$ ) and by the radar network for the precipitation event between 30 May 2004 19:30 UTC and 31 May 2004 23:30 UTC (altogether 46 scenes).

\begin{tabular}{ccccccccc}
\hline & Pixel ACT & Pixel & Bias & POD & FAR & CSI & ETS & HSS \\
\hline ID1 & 255 & 96 & 2.7 & 0.0 & 1.0 & 0.0 & 0.0 & 0.0 \\
ID2 & 1189 & 623 & 1.91 & 0.0 & 1.0 & 0.0 & 0.0 & 0.0 \\
ID3 & 16012 & 10592 & 1.51 & 0.16 & 0.9 & 0.08 & 0.02 & 0.0 \\
ID4 & 76712 & 102282 & 0.75 & 0.72 & 0.13 & 0.65 & 0.05 & 0.02 \\
\hline
\end{tabular}

intensities at the surface. The winds within the cloud and below the cloud bottom can displace the rain drops and cause the displayed spatial misalignments. This explanation holds also true for the higher spatial extend of the classified subareas, especially for ID 1 to ID 3, yielding the overestimation for these IDs. The high rainfall intensities detected by the new classification scheme from above might weaken between the cloud top and its bottom and therefore result in lower intensities in the radar product. The cloud microstructure and precipitation forming processes within the cloud together with the wind field within and below the cloud can be responsible for a smaller areal extension and a decreasing rainfall intensity of the detected precipitation area below the cloud in comparison to the detected rain area by the satellite from above. Because of the indirect nature of the relationship between rainfall and IR cloud top temperature it is therefore possible that the detected rain area by means of the IR temperature threshold is larger than the rain area detected by the radar.

The calculated indices POD, FAR, CSI, ETS, and HSS indicate best results for ID 4 followed by ID 3 . The low values of ETS and HSS which both account for pixels correctly classified by chance compared to the CSI indicate that a relatively high proportion of the pixels are randomly classified as the respective ID. This phenomenon has to be analysed in more detail during extensive validation studies.

The indices for ID 1 and ID 2 indicate no skill of the new technique in comparison to the radar data. This can be explained by the potential spatial misalignments between both retrieval techniques together with the low absolute pixel amount for these subareas. Because of the lower fraction of the classified subareas these spatial misalignments have a strong influence on the quality of the calculated scores for both IDs. As the area of ID 4 is classified from the remaining pixels within the rain area that are not classified as ID 1, ID 2 or ID 3, an overestimation of the first three IDs leads to an underestimation of ID 4.

To gain a visual impression of the performance of the new proposed process-oriented classification scheme Fig. 4 illustrates a case study for 31 May 2004 00:45 UTC. Figure 4 a shows the result of the classification scheme. The reflectivity classes detected by the ground based radar data from the German Weather Service (DWD, 2005) representing dif- ferent rainfall intensities, are displayed in Fig. 4b. The cloud area displayed in Fig. $4 \mathrm{a}$ and $\mathrm{b}$ is classified from satellite data by using the cloud mask proposed by Cermak et al. (2006). The radar were first projected to the SEVIRI viewing geometry.

\section{Conclusions}

The potential for a process-oriented rain area classification using Meteosat Second Generation SEVIRI nighttime was analysed. The proposed technique is based on a combination of the Advective Convective Technique and the Rain Area Delineation Scheme during Nighttime.

The ACT which considers positive $\Delta T_{\mathrm{WV}-\mathrm{IR}}$ for the detection of convective clouds and connected precipitating clouds has been transferred from MVIRI to SEVIRI. SEVIRI $\Delta T_{\mathrm{WV} 7.3-I R 12.1}$ combination was identified as the appropriate channel combination to reproduce the results of the MVIRI based ACT.

RADS-N is based on the new conceptual model that precipitation is favoured by a large cloud water path and the presence of ice particles in the upper part of the cloud. The technique considers information about both parameters inherent in the channel differences $\Delta T_{3.9-10.8}, \Delta T_{3.9-7.3}$, $\Delta T_{8.7-10.8}$, and $\Delta T_{10.8-12.1}$, to detect potentially precipitating cloud areas. All four channel differences are used to gain implicit knowledge about the $c w p . \Delta T_{8.7-10.8}$ and $\Delta T_{10.8-12.1}$ are additionally considered to gain information about the cloud phase.

For a first appraisal, the classified rain areas by the introduced technique were compared with corresponding ground based radar data for a precipitation event in May 2004. The results indicate encouraging performance of the proposed technique and support the possibility of process-oriented classification of the detected rain area into subareas with different rainfall intensities.

The presented study shows that the phenomenon of positive $\Delta T_{\mathrm{WV}-\mathrm{IR}}$ is applicable to SEVIRI and can be used to identify convective rain clouds. The differences between the four WV-IR combinations are explained by means of radiative transfer calculations. Based on the obtained results it can be stated that a transfer of the ACT from MVIRI to SEVIRI 


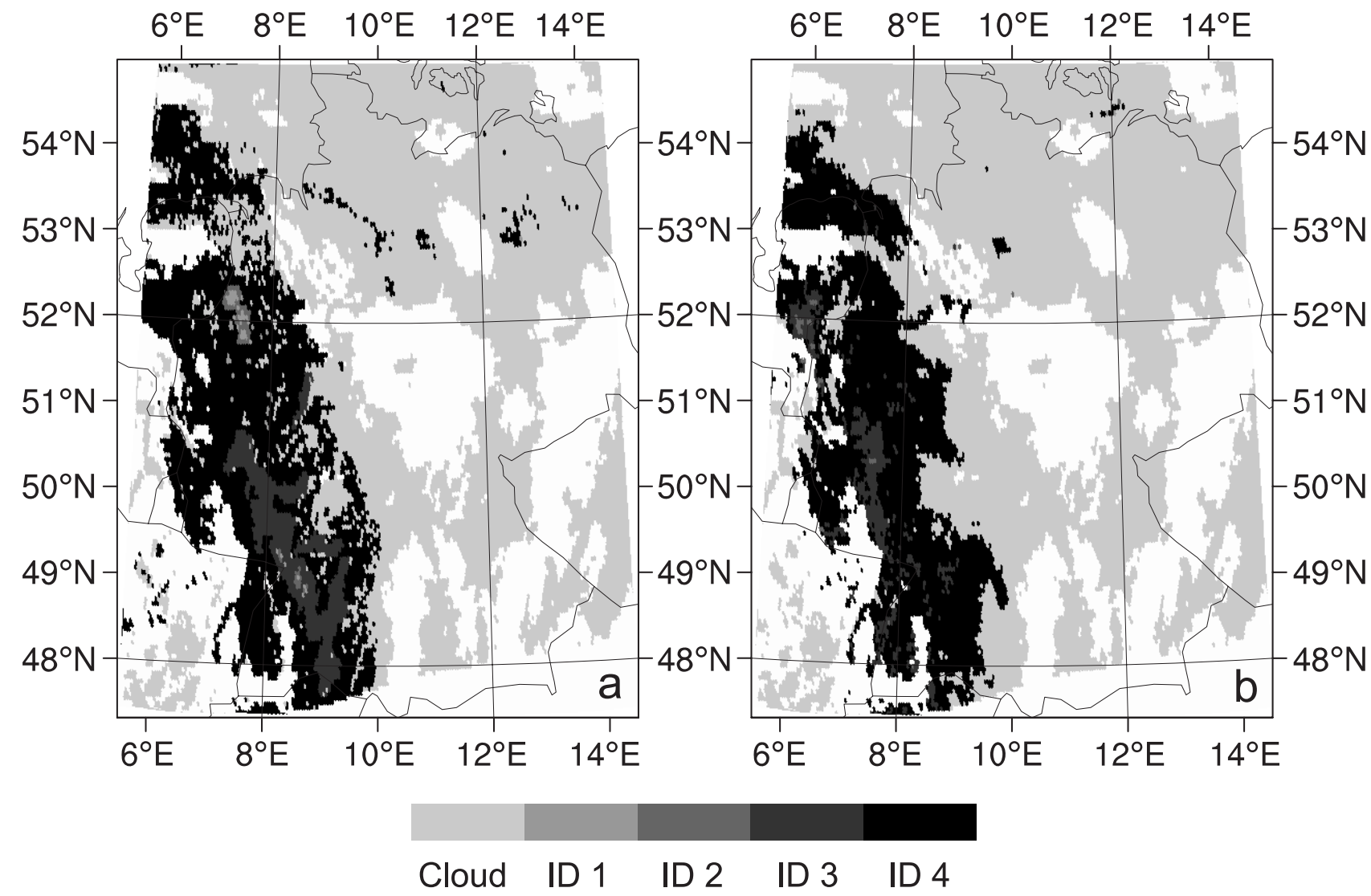

Fig. 4. Result of the new process-oriented differentiation scheme (ACT plus RADS-N) (a) in comparison to the result of the radar network (b) for 31 May 200400.45 UTC.

is possible even under the restriction of the differing spectral resolution between MVIRI and SEVIRI. Nevertheless, more detailed studies are needed to analyse the potential offered by the enhanced spectral resolution of SEVIRI regarding an improvement of the ACT. Here, the presented results can help to identify potential weaknesses of the technique that can be tackled for possible improvements.

One major objective concerning a successful transfer of the ACT to SEVIRI presents the continuation beyond MVIRI in order to gain long time series of satellite-retrieved rainfall data applicable to climate change studies. Another important aspect regarding the transfer of the ACT to SEVIRI is the possibility of a process classification within the detected rain area. An improved detection of the precipitating cloud areas is the precondition for such a classification. In this context the mentioned RADS-N represents an improvement concerning the rain area delineation based on the enhanced spectral resolution of SEVIRI. This is especially true for precipitating cloud areas formed by widespread frontal lifting processes in connection with extra-tropical cyclones. Based on the improved rain area delineation the classification of different rainfall processes within the rain area presents an important step regarding an improved rainfall rate assignment which forms the second step of satellite based rainfall retrievals.

In view of an improved rainfall retrieval using SEVIRI data, the present study should be considered as a first investigation to analyse the potential of a possible process classification within the detected rain area based on multispectral satellite data. In this context the results of the RADS-N have already demonstrated the high potential of SEVIRI concerning an improved rain area delineation.

The presented results show that a process classification is possible by combining a conventional IR retrieval for convective precipitation processes with a new and improved rain area delineation scheme based on the enhanced spectral resolution offered by next generation weather satellites.

However, extensive and more detailed investigation is needed to further improve and refine the classification of different precipitation processes within the rain area. In this context, special attention must be laid on the potential offered by the enhanced spectral resolution of SEVIRI.

Acknowledgements. The current study is funded by the German Ministry of Research and Education (BMBF) in the framework of GLOWA-Danube project (G-D/2004/TP-10, precipitation/remote 
sensing) as well as by the German Research Council DFG (BE 1780/18-1) within the SORT project.

The authors are grateful to the German weather service (DWD) for providing the radar datasets within the Eumetsat/DWD Advanced Multisensor Precipitation Experiment (AMPE).

Edited by: S. C. Michaelides

Reviewed by: two anonymous referees

\section{References}

Adler, R. F. and Negri, A. J.: A satellite technique to estimate tropical convective and stratiform rainfall, J. Appl. Meteorol., 27, 30-51, 1988.

Bendix, J.: Adjustment of the Convective-Stratiform Technique to estimate 1991/92 El Nino rainfall distribution in Ecuador and Peru by means of Meteosat-3 data, International Journal of Remote Sensing, 18, 1387-1394, 1997.

Bradley, P. S. and Fayyad, U. M.: Refining Initial Points for KMeans Clustering, In: Shavlik, J. (Edt.): Proceedings of the 15th International Conference on Machine Learning, 91-99, 1998.

Cermak, J., Schneebeli, M., Nowak, D., Vuilleumier, L., and Bendix, J.: Characterization of Low Clouds With Satellite and Ground-Based Remote Sensing Systems, Meteorologische Zeitschrift, 15, 65-72, 2006.

DWD: Weather radar network, available online at http: //www.dwd.de/en/Technik/Datengewinnung/Radarverbund/ Radarbroschuere_en.pdf, last access: 11 October 2007.

Ebert, E. E., Janowiak, J. E., and Kidd, C.: Comparison of nearreal-time precipitation estimates from satellite observations and numerical models, B. Am. Meteorol. Soc., 88, 47-64, 2007.

Fritz, S. and Laszlo, I.: Detection of water vapor in the stratosphere over very high clouds in the tropics, Journal of Geophysical Research, 98(D12), 22 959-22 967, 1993.

Früh, B., Bendix, J., Nauss, T., Paulat, M., Pfeiffer, A., Schipper, J. W., Thies, B., and Wernli, H.: Verification of precipitation from regional climate simulations and remote-sensing observations with respect to ground-based observations in the upper Danube catchment, Meteorologische Zeitschrift, 16, 275-293, 2007.

Houze, R. A.: Cloud Dynamics, Vol. 53 of the International Geophysics Series, Academic Press, San Diego, 1993.

Key, J.: Streamer User's Guide, Cooperative Institute for Meteorological Satellite Studies, University of Wisconsin, 2001.

Key, J. and Schweiger, A.J.: Tools for atmospheric radiative transfer: Streamer and FluxNet, Computers and Geosciences, 24, 443-451, 1998.

Kleespies, T. J. and McMillin, L. M.: Retrieval of precipitable water from observations in the split window over varying surface temperatures, J. Appl. Meteorol., 29, 851-862, 1990.

Kley, D., Schmeltekopf, A., Kelly, K., Winkler, R., Thompson, T., and McFarland, M.: Transport of water vapour through the tropical tropopause, Geophys. Res. Lett., 9, 617-624, 1982.

Kurino, T.: A satellite infrared technique for estimating 'deep/shallow' precipitation, Advances in Space Research, 19, 511-514, 1997.
Lang, P.: Niederschlagsquantifizierung auf der Basis von Radardaten, Promet 26, 22-32, 1997.

Levizzani, V.: Satellite rainfall estimations: new perspectives for meteorology and climate from the EURAINSAT project, Ann. Geophys., 46, 363-372, 2003, http://www.ann-geophys.net/46/363/2003/.

Levizzani, V., Schmetz, J., Lutz, H. J., Kerkmann, J., Alberoni, P. P., and Cervino, M.: Precipitation estimations from geostationary orbit and prospects for Meteosat Second Generation, Meteorol. Appl., 8, 23-41, 2001.

Page, W.: NASA experiment on tropospheric-stratospheric water vapour transport in the intertropical convergence zone, Geophys. Res. Lett., 9, 599-624, 1982.

Reudenbach, C., Heinemann, G., Heuel, E., Bendix, J., and Winiger, M.: Investigation of summertime convective rainfall in Western Europe based on a synergy of remote sensing data and numerical models, Meteorol. Atmos. Phys., 76, 23-41, 2001.

Reudenbach, C.: Konvektive Sommerniederschlge in Mitteleuropa. Eine Kombination aus Satellitenfernerkundung und numerischer Modellierung zur automatischen Erfassung mesoskaliger Niederschlagsfelder, Bonner Geographische Abhandlungen, 109, 2003.

Reudenbach, C., Nauss, T., and Bendix, J.: Retrieving precipitation with GOES, Meteosat and Terra/MSG at the tropics and midlatitudes, In: Measuring precipitation form space, edited by: Levizzani, V., Bauer, P., and Turk, F.J., Advances in Global Change Research, 28, 2007.

Schemenauer, R. B. and Isaac, G. A.: The importance of cloud top lifetime in the description of natural cloud characteristics, J. Clim. Appl. Meteorol., 23, 267-279, 1984.

Schmetz, J., Tjemkes, S. A., Gube, M., and van de Berg, L.: Monitoring deep convection and convective overshooting with Meteosat, Adv. Space Res., 19, 433-441, 1997.

Schmetz, J., Pili, P., Tjemkes, S., Just, D., Kerkmann, J., Rota, S., and Ratier, A.: An introduction to Meteosat Second Generation (MSG), B. Am. Meteorol. Soc., 83, 977-992, 2002.

Seltmann, J.: Radarforschung im DWD: Vom Scan zum Produkt., Promet 26, 32-52, 1997.

Stanski, H. R., Wilson, L., and Burrows, W.: Survey of common verification methods in meteorology, World Weather Watch Technical Report No. 8, WMO, Geneva, WMO/TD No. 358, 1989.

Thies, B., Nauss, T., and Bendix, J.: Discriminating raining from non-raining cloud areas at mid-latitudes using Meteosat Second Generation SEVIRI nighttime data, Meteorol. Appl., in press, 2008.

Tjemkes, S. A., van de Berg, L., and Schmetz, J.: Warm water vapour pixels over high clouds as observed by Meteosat, Contributions to atmospheric physics, 70, 15-21, 1997.

World Weather Research Program/Working Group on Numerical Experimentation Joint Working Group on Verification (WWRP/WGNE): Forecast Verification - Issues, Methods and FAQ, available online at http://www.bom.gov.au/bmrc/wefor/ staff/eee/verif/verif_web_page.html, 11 October 2007.

Zhang, G., Xu, L., and Hongbin, C.: A new parameterization scheme for short-wave radiative properties of water clouds, J. Appl. Meteorol., 34, 101-106, 1995. 